\title{
(6) OPEN ACCESS \\ What methods are used to apply positive deviance within healthcare organisations? A systematic review
}

\author{
Ruth Baxter, ${ }^{1,2}$ Natalie Taylor, ${ }^{2,3}$ Ian Kellar, ${ }^{1,2}$ Rebecca Lawton ${ }^{1,2}$
}

- Additional material is published online only. To view please visit the journal online (http://dx.doi.org/10.1136/bmjqs2015-004386)

${ }^{1}$ School of Psychology, University of Leeds, Leeds, Yorkshire, UK ${ }^{2}$ Quality and Safety Research Group, Bradford Institute for Health Research, Bradford, UK

${ }^{3}$ Centre for Healthcare Resilience and Implementation Science, Australian Institute of Health Innovation, Faculty of Medicine and Health Sciences, Macquarie University, Sydney, New South Wales, Australia

\section{Correspondence to}

Ruth Baxter, School of Psychology, University of Leeds, Lifton Place, Leeds, Yorkshire LS2 9JZ, UK.

ps12rmb@leeds.ac.uk

Received 12 May 2015 Revised 28 September 2015 Accepted 4 October 2015 Published Online First 20 November 2015

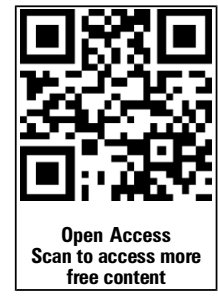

CrossMark

To cite: Baxter R, Taylor $\mathrm{N}$ Kellar I, et al. BMJ Qual Saf 2016;25:190-201.

\begin{abstract}
Background The positive deviance approach focuses on those who demonstrate exceptional performance, despite facing the same constraints as others. 'Positive deviants' are identified and

involve staff and patients in all stages of the positive deviance approach. The efficacy and efficiency of positive deviance must be assessed and compared with other quality improvement approaches.
\end{abstract} hypotheses about how they succeed are generated. These hypotheses are tested and then disseminated within the wider community. The positive deviance approach is being increasingly applied within healthcare organisations, although limited guidance exists and different methods, of varying quality, are used. This paper systematically reviews healthcare applications of the positive deviance approach to explore how positive deviance is defined, the quality of existing applications and the methods used within them, including the extent to which staff and patients are involved.

Methods Peer-reviewed articles, published prior to September 2014, reporting empirical research on the use of the positive deviance approach within healthcare, were identified from seven electronic databases. A previously defined fourstage process for positive deviance in healthcare was used as the basis for data extraction. Quality assessments were conducted using a validated tool, and a narrative synthesis approach was followed.

Results 37 of 818 articles met the inclusion criteria. The positive deviance approach was most frequently applied within North America, in secondary care, and to address healthcareassociated infections. Research predominantly identified positive deviants and generated hypotheses about how they succeeded. The approach and processes followed were poorly defined. Research quality was low, articles lacked detail and comparison groups were rarely included. Applications of positive deviance typically lacked staff and/or patient involvement, and the methods used often required extensive resources.

Conclusion Further research is required to develop high quality yet practical methods which

\section{PROSPERO registration number}

CRD42014009365

\section{BACKGROUND}

Within healthcare, various approaches to patient safety and quality improvement exist. Traditionally these approaches are deficit-based; they focus on identifying and learning from past harm. Their effectiveness is limited as only two-thirds of improvement projects achieve their objectives and deliver sustainable change. ${ }^{1}$ Improvements are often shortlived, fail to reach the most disadvantaged and can create unintended consequences. $^{2} \quad 3$ Furthermore, various challenges are faced while using these approaches such as engaging front-line staff, addressing their most pertinent issues and adequately accounting for context. $^{2}{ }^{3}$ Change is often introduced from the top of organisations and/or by external experts, and additional resources are rarely provided to support this. ${ }^{1}$

The need to 'flip healthcare on its head' has recently been suggested. ${ }^{4}$ Despite our negativity, safe, high-quality care is reliably delivered the majority of the time. ${ }^{5}$ Asset-based approaches, which focus on the strengths and resources of a community, recognise this and explore how, and why, things go right in order to learn from these successes. One such approach, 'positive deviance', is increasingly being applied within healthcare settings and has the potential to address a number of the challenges faced when trying to improve quality. 
An alternative approach to quality improvement

Positive deviance is a bottom-up approach which identifies and learns from those who demonstrate exceptional performance on an outcome of interest. The approach assumes that problems can be overcome using solutions that already exist within communities. $^{6} 7$ Despite facing the same constraints as others, 'positive deviants' identify these solutions and succeed by demonstrating uncommon or different behaviours. Community involvement is integral to the approach, for example, staff select the problem to address, identify the positive deviants and explore how they succeed. Solutions are internally generated rather than externally imposed, ensuring that they are feasible within current resources, acceptable to others and sustainable over time. ${ }^{8}$

Specifically within healthcare, Bradley et al have proposed a four-stage process for adopting the positive deviance approach (figure 1). ${ }^{7}$ Positive deviants with exceptionally high performance are identified using widely endorsed routinely collected data (stage 1). Qualitative methods are used to generate hypotheses about how positive deviants succeed (stage 2). These hypotheses are tested within larger, more representative samples (stage 3 ) and, finally, the successful, positively deviant practises are disseminated widely (stage 4).

\section{Positive deviance in practise}

The positive deviance approach originated within international public health. It has been used within settings such as business ${ }^{9}$ and more recently has been applied to healthcare. ${ }^{8}$ Bradley $\mathrm{et}^{\mathrm{al}} \mathrm{l}^{7}$ used the approach to increase guideline adherence for the treatment of acute myocardial infarction. Positively deviant hospitals were identified using national registry data and factors that facilitated success were explored. Those which statistically improved outcomes were disseminated through a public campaign, and guideline

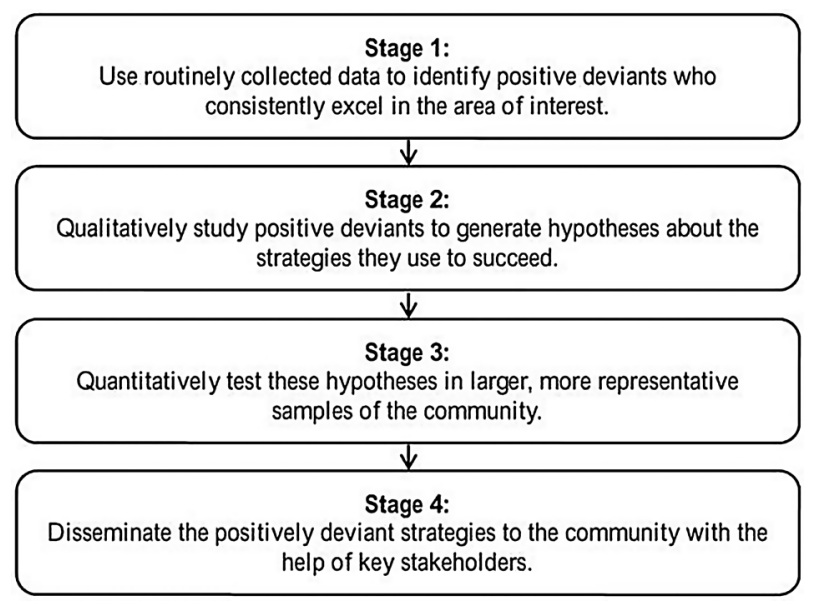

Figure 1 The positive deviance process for healthcare organisations (adapted from ref. 7). adherence rose by $25 \%$, which, in turn, increased patient survival. $^{7}$

Despite successes, current understanding of how the positive deviance approach works, and evidence regarding its effectiveness is limited. Although Bradley et al's healthcare-specific process exists, there is limited guidance on how to operationalise each step. ${ }^{8}$ Positive deviants are identified using many different methods, some of which appear to lack validity and/ or reliability such as selecting annual award winners. ${ }^{10}$ Furthermore, the extent to which each stage of the process is implemented may be limited, hindering assessment of the approach's efficacy. ${ }^{8}$ For example, Kim et al. ${ }^{11}$ explored how positively deviant nurses and patients effectively communicated family planning issues, but did not explain how they would assess whether these behaviours improved outcomes. Further guidance is required to help identify and classify positive deviants, select the methods used at each stage, involve front-line staff and patients in the process and effectively disseminate findings. ${ }^{8}$

\section{Objectives}

A previous systematic review assessed the effectiveness of positive deviance in reducing childhood malnutrition. ${ }^{12}$ Although the author described study methods, the research settings (rural villages and low/ middle-income countries) differed dramatically from well-developed, complex healthcare organisations. The current systematic review synthesises applications of the positive deviance approach within healthcare organisations to better characterise the challenges faced, and to provide guidance for those implementing the approach. The following questions will be addressed:

- How is positive deviance defined?

- What study designs and methods are used at each stage of the positive deviance process?

- What is the quality of existing research?

- To what extent are staff and patients involved in the approach?

\section{METHODS}

\section{Search strategy}

This systematic review adheres to the Preferred Reporting Items for Systematic Reviews and Meta-Analyses statement (PRISMA-see online supplementary file 1), ${ }^{13}$ and the protocol was published on PROSPERO. ${ }^{14}$ The search term, 'positive devian", identified articles relating to positive deviance and positive deviants. Search terms for 'high performance' and 'positive outliers' were excluded as they lacked specificity and identified large numbers of irrelevant articles. Studies conducted within healthcare organisations were selected for inclusion. The search strategy was applied to PsycINFO, MEDLINE, Web of Science, Cochrane Library, Embase, CINAHL and Global Health Database in January 2014 and updated 
in September 2014. Time restrictions were excluded to maximise the identification of relevant literature. The search strategy, time periods searched for each database and full results are detailed in online supplementary file 2 .

\section{Eligibility criteria and study selection}

The inclusion criteria are outlined in table 1. One reviewer (RB) screened titles and abstracts and then conducted a full-text review, meeting regularly with second reviewers to discuss article eligibility. At both stages, $10 \%$ of randomly selected articles were independently second reviewed by IK, RL and NT (title and abstract, $n=83$; full text review, $n=36$ ). Inter-rater reliability was assessed using a Kappa statistic. ${ }^{15}$ Substantial agreement $(\mathrm{k}=0.64)$ existed between reviewers for the title and abstract review, and strong agreement $(\mathrm{k}=0.87)$ existed for the full-text review. Discrepancies were resolved either through a full-text review or by discussion. Reasons for exclusion were recorded, and reference list and citation searches were conducted for all included articles.

\section{Study quality assessment}

The positive deviance approach uses quantitative and qualitative methods; however, quality assessment tools typically evaluate these study designs separately. ${ }^{16}$ The Quality Assessment Tool for Studies with Diverse Designs (QATSDD) is a validated tool that standardises the quality assessment of research with heterogeneous study designs. ${ }^{16}$ A total of 16 items are scored using 4-point Likert scales and guidance notes to reduce subjectivity. All items are relevant to mixedmethods research, 14 items are relevant to qualitative

Table 1 Eligibility criteria for inclusion of articles in the review

\begin{tabular}{ll}
\hline PICOS & Details of eligibility \\
\hline Population & $\begin{array}{l}\text { Conducted within and/or involving the contribution of } \\
\text { healthcare organisations (primary care, secondary care and } \\
\text { national-level organisations). }\end{array}$ \\
& $\begin{array}{l}\text { Articles were excluded if healthcare organisations were not } \\
\text { directly involved, for example if the sole focus was on } \\
\text { patient behaviours }\end{array}$ \\
Intervention & $\begin{array}{l}\text { Explicit use of the 'positive deviance' approach, applied on } \\
\text { its own or within a complex intervention }\end{array}$ \\
Comparison & $\begin{array}{l}\text { Positively deviant individuals or groups could be compared } \\
\text { Outcome }\end{array}$ \\
with any other group or individual \\
Study & $\begin{array}{l}\text { The positive deviance approach could be applied to address } \\
\text { any outcome, behaviour and/or quality improvement issue }\end{array}$ \\
design & $\begin{array}{l}\text { Peer reviewed reports of empirical research were included. } \\
\text { Peer reviewed editorials reporting the results of empirical } \\
\text { research were also included. } \\
\text { General editorials on the approach, non-peer reviewed } \\
\text { articles and grey literature were excluded to provide an } \\
\text { additional level of quality control, and to reflect the } \\
\text { grounding of healthcare within evidence-based practice. } \\
\text { Articles were included regardless of their study design, date } \\
\text { or country of origin. It was only possible to include studies } \\
\text { published in the English language due to limited resource }\end{array}$ \\
\hline
\end{tabular}

research and 14 items are relevant to quantitative research. Included articles were assessed using QATSDD and quality was expressed as a percentage. All reviewers assessed three articles and compared results to ensure that the tool was applied consistently. $\mathrm{RB}$ completed the remaining quality assessments which were second reviewed by IK, RL and NT. Discrepancies were resolved by discussion and articles were included regardless of outcomes.

\section{Data extraction and synthesis}

A data extraction form was piloted to ensure effective and consistent use. Data were extracted for the following broad areas (see online supplementary file 3 which provides full details): (1) general information on the positive deviance project including the aims, setting and outcomes/behaviours explored; (2) the definition of positive deviance used and the process followed and (3) the methods used to apply the positive deviance approach at each stage of the Bradley et al process (figure 1-all studies could be coded according to these four stages). ${ }^{7}$ Data were extracted by RB, second reviewed by RL, IK or NT, and discrepancies were resolved by discussion.

The heterogeneous study designs, settings, behaviours and outcomes precluded a meta-analysis or effectiveness review; therefore where relevant, Popay et al's guidance for narrative synthesis was followed. ${ }^{17-19}$ Their iterative framework is complemented by tools and techniques which can be used to synthesise literature. ${ }^{17}$ Initially a theory is developed of how, why and for whom an intervention works. This aspect of the synthesis is not always conducted, and for this review it lacked relevance to the aims and heterogeneous articles. Groupings and clusters, tabulation, vote counting and thematic analysis were then used to develop a preliminary synthesis. Relationships within the data were explored using textual/qualitative case descriptions, and finally, the robustness of the synthesis was assessed using critical reflections and validity assessments. ${ }^{17}$

\section{RESULTS}

The search strategy yielded 818 articles excluding duplicates and 7 articles were identified through reference list and citation searches. In total, 37 articles were included representing 22 distinct positive deviance projects (figure 2). Articles were primarily excluded for not explicitly using the positive deviance approach.

The key characteristics of included articles are outlined in table 2. The positive deviance approach was most frequently applied in North America, within secondary care settings, and to address healthcare-associated infections and/or hand hygiene problems. Other applications include nurse-patient communication within Indonesian public clinics, ${ }^{11}$ clinical achievement within Pakistani medical schools ${ }^{41}$ and 


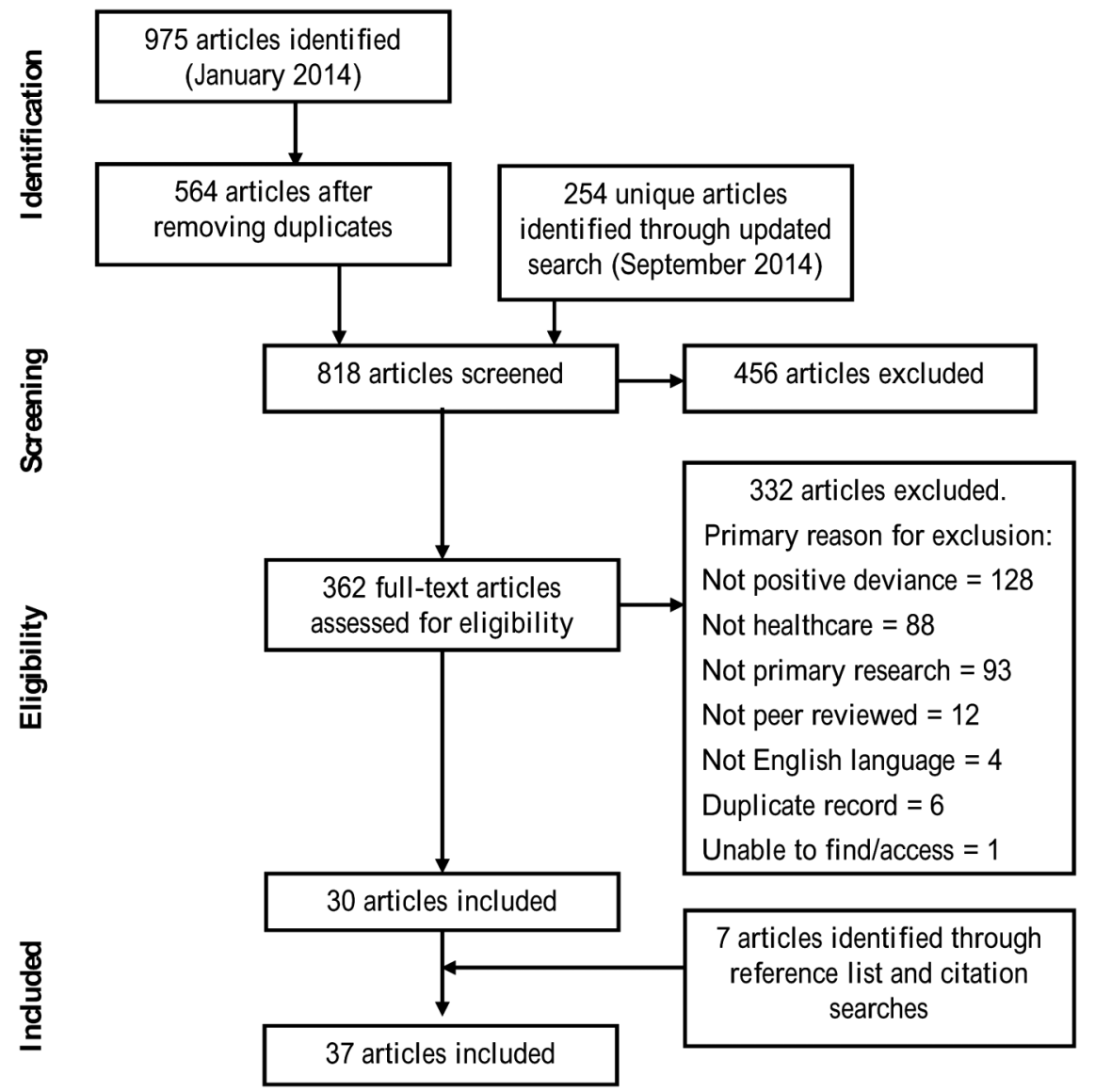

Figure 2 Flowchart summarising study selection.

immunisation coverage across Africa. ${ }^{52}$ A vote count highlighted that stages 1 and 2 of the Bradley et al process ${ }^{7}$ were most frequently addressed-identifying positive deviants and generating hypotheses about how they succeed (table 2). Hypotheses were rarely tested or disseminated (stages 3 and 4). About 73\% of articles were published after 2011, and study quality was predominantly low, ranging from $2.1 \%$ to $50.0 \%$.

\section{Positive deviance definitions}

Definitions of the positive deviance approach were thematically analysed to reveal four key themes (table 3). Positive deviants were defined as high performers who demonstrated different or uncommon behaviours. Community involvement is integral to the approach and positively deviant behaviours should be sustainable and feasible within current resources. Most definitions lacked detail with few containing all four themes. ${ }^{24} 34364346$ Some articles did not define positive deviance at all. ${ }^{20} \quad 30-32 \quad 42 \quad 45 \quad 54$ Conceptualisations of the approach also varied. Community involvement was central to Anzarut et al's definition, ${ }^{28}$ while Kennedy $e t$ al ${ }^{33}$ emphasised that determinants of success do not necessarily oppose determinants of failure. Positive deviance was commonly used as a single improvement method, but 26 articles did not explicitly state which process had been followed (see online supplementary file 4). Where details were provided, the Bradley et al's four-stage process ${ }^{7}$ was most commonly followed (six articlessee online supplementary file 4 ).

\section{Study design and methods}

Stage 1-identifying positive deviants

Positively deviant organisations, teams and/or individuals were not explicitly identified in 2 of the 22 distinct projects. ${ }^{26-28}$ Instead, success was explored without prior assessment or knowledge of performance (stage 2). It was unclear whether positive deviants were identified within some of the Veterans Affairs literature, ${ }^{42} \quad 43 \quad 45 \quad 47$ and Lindberg and Schneider ${ }^{34}$ identified positively deviant behaviours rather than individuals or groups.

Positive deviants were identified quantitatively in 13

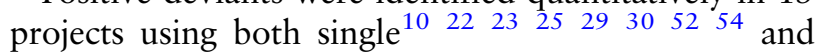
composite measures $^{21} 20414953$ (see online supplementary file 4). Eight of these projects used routinely collected data, although, case notes, nurse-patient consultations, non-routine data and national awards were also used. ${ }^{10} 113341$ Positive deviants were identified less frequently using qualitative methods including peer recommendation, document analysis, observation and mixed-method combinations of the above (see online supplementary file 4). 


\begin{tabular}{|c|c|c|c|c|c|c|c|}
\hline \multirow[b]{2}{*}{ Author and year } & \multirow[b]{2}{*}{ Location } & \multirow[b]{2}{*}{ Healthcare setting } & \multirow[b]{2}{*}{ Problem or issue addressed } & \multicolumn{4}{|c|}{$\begin{array}{l}\text { Stages } \\
\text { addressed: * }\end{array}$} \\
\hline & & & & 1 & 2 & 3 & 4 \\
\hline \multicolumn{8}{|l|}{ Primary care } \\
\hline Bradley et al $2012^{54}$ & Ethiopia, four regions & Primary Healthcare Units & Quality, access and usage of primary healthcare in rural, low-income settings & Y & Y & N & N \\
\hline Gabbay et al $2013^{21}$ & USA, Pennsylvania & Primary Care Medical Homes & Variation in diabetes care across medical home practices & Y & Y & N & N \\
\hline Taliani et al $2013^{20}$ & USA, Pennsylvania & Primary Care Medical Homes & Variation in the definition and implementation of care manager roles & Y & Y & $\mathrm{N}$ & N \\
\hline Kim et al $2008^{11}$ & Indonesia, East Java & Public clinics & Nurse-patient communication within a family planning context & Y & Y & $\mathrm{N}$ & N \\
\hline Kraschnewski et al $2013^{22}$ & USA, national & Primary care providers & $\begin{array}{l}\text { The provision of advice to obese and overweight adults on weight loss/setting weight-loss } \\
\text { goals }\end{array}$ & Y & Y & N & N \\
\hline Ma and Magnus $2012^{23}$ & USA, Los Angeles & Community public health & $\begin{array}{l}\text { Black mothers and women with low education or socioeconomic status have } \\
\text { lower initiation of breastfeeding }\end{array}$ & Y & Y & $\mathrm{N}$ & $\mathrm{N}$ \\
\hline Marsh et al $2002^{24}$ & Pakistan, Haripur & Primary care & Infant mortality ratio & Y & Y & $\mathrm{N}$ & Y \\
\hline Rose et al $2012^{25}$ & USA, national & VMSCs - primary care & Substantial variation in anticoagulation control & Y & Y & $\mathrm{N}$ & N \\
\hline \multicolumn{8}{|l|}{ Secondary care } \\
\hline Abrahamson et al $2011^{26}$ & USA, Indiana & Cancer care organisations & Clinical practice to manage psychosocial distress in patients with cancer & N & Y & N & N \\
\hline Abrahamson et al $2011^{27}$ & USA, Indiana & Cancer care organisations & Clinical practice to manage psychosocial distress in patients with cancer & N & Y & N & N \\
\hline Anzarut et al $2011^{28}$ & Inferred as Canada & Inferred as acute hospital & Unsatisfactory plastic surgery journal clubs & N & Y & Y & N \\
\hline Curry et al $2011^{29}$ & USA, national & Acute hospitals & $\begin{array}{l}\text { Variation in } 30 \text { days risk standardised mortality ratio (RSMR) for patients with acute } \\
\text { myocardial infarction (AMI) }\end{array}$ & Y & Y & $\mathrm{N}$ & N \\
\hline Cherlin et al $2012^{30}$ & USA, national & Acute hospitals & $\begin{array}{l}\text { Variation in } 30 \text { days RSMR for patients with AMI. One-third of deaths contributing } \\
\text { to RSMR occur after discharge }\end{array}$ & Y & Y & $\mathrm{N}$ & N \\
\hline Bradley et al $2012^{31}$ & USA, national & Acute hospitals & Variation in 30 days RSMR for patients with AMI & N & $\mathrm{N}$ & Y & N \\
\hline Landman et al $2013^{32}$ & USA, national & Acute hospitals and emergency services & $\begin{array}{l}\text { Collaboration between hospital and emergency services to reduce variability } \\
\text { in RSMR for patients with AMI }\end{array}$ & N & Y & N & N \\
\hline Griffith et al $2013^{10}$ & USA, national & Healthcare organisations & Use of knowledge management within healthcare practises & Y & Y & N & N \\
\hline Kennedy et al $1999^{33}$ & USA, Mid-West & Children developmental clinics & $\begin{array}{l}\text { Infants with very low birthweight are at higher risk of clinical problems. } \\
\text { Premature infants who grow well have better developmental outcomes }\end{array}$ & Y & Y & N & N \\
\hline $\begin{array}{l}\text { Lindberg and Schneider } \\
2013^{34}\end{array}$ & USA, Maine & $\begin{array}{l}\text { Medical centre (including community } \\
\text { hospital/tertiary care) }\end{array}$ & MRSA infections & $\mathrm{N}$ & Y & N & Y \\
\hline Lindberg et al $2013^{35}$ & USA, New Jersey & Outpatient haemodialysis centre & Blood stream infections & Y & Y & N & $\mathrm{N}$ \\
\hline Downham et al $2012^{36}$ & USA, New Jersey & Outpatient haemodialysis centre & Blood stream infections & N & Y & N & Y \\
\hline Marra et al $2010^{37}$ & Brazil & Hospital Step Down Units & Hand hygiene compliance & Y & Y & N & N \\
\hline Marra et al $2011^{38}$ & Brazil & Hospital Step Down Units & Hand hygiene compliance & Y & Y & N & N \\
\hline De MacEdo et al $2012^{39}$ & Brazil, Sao Paulo & Hospital Step Down Units & Hand hygiene compliance & $\mathrm{N}$ & Y & N & N \\
\hline Marra et al $2013^{40}$ & Brazil and Thailand & Hospitals (1 ward, 8 intensive care units) & Hand hygiene compliance & N & N & Y & N \\
\hline Zaldi et al $2012^{41}$ & Pakistan & Medical school & $\begin{array}{l}\text { Student achievement in preclinical written work often does } \\
\text { not reflect achievement in clinical work }\end{array}$ & Y & Y & Y & N \\
\hline
\end{tabular}

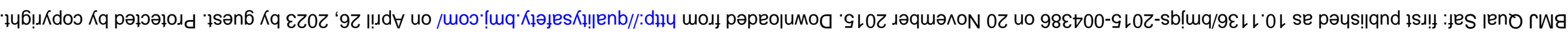




\begin{tabular}{|c|c|c|c|c|c|c|c|}
\hline \multirow[b]{2}{*}{ Author and year } & \multirow[b]{2}{*}{ Location } & \multirow[b]{2}{*}{ Healthcare setting } & \multirow[b]{2}{*}{ Problem or issue addressed } & \multicolumn{4}{|c|}{$\begin{array}{l}\text { Stages } \\
\text { addressed: * }\end{array}$} \\
\hline & & & & 1 & 2 & 3 & 4 \\
\hline Awad et al $2009^{42}$ & USA, Houston & 1 VAMC & Incidence of MRSA surgical site infections & $?$ & N & Y & Y \\
\hline Bonuel et al $2009^{43}$ & USA, Houston & 1 VAMC & Increased incidence MRSA infection and inconsistent application of prevention methods & $?$ & $\mathrm{~N}$ & Y & $\mathrm{N}$ \\
\hline Ellingson et al $2011^{44}$ & USA, North-East & 1 VAMC & Antimicrobial (MRSA) resistance in US healthcare facilities & Y & Y & N & N \\
\hline Evans et al $2013^{45}$ & USA, national & VAMCs (Spinal Cord Injury Units) & $\begin{array}{l}\text { Patients with spinal cord injury are at higher risk of developing healthcare-associated } \\
\text { infections such as MRSA }\end{array}$ & $?$ & N & N & Y \\
\hline $\begin{array}{l}\text { Forsha and Richmond } \\
2007^{46}\end{array}$ & $\begin{array}{l}\text { USA —VA Pittsburgh Healthcare } \\
\text { System }\end{array}$ & $\begin{array}{l}\text { Acute, long-term and behavioural } \\
\text { services }\end{array}$ & Reduction of healthcare-associated Staphylococcus aureus infections such as MRSA & Y & Y & N & $?$ \\
\hline Jain et al $2011^{47}$ & USA, national & $\begin{array}{l}\text { VAMCs (intensive care/non-intensive care } \\
\text { units) }\end{array}$ & Reduction of MRSA infections in acute care facilities & $?$ & N & N & Y \\
\hline \multicolumn{8}{|l|}{ Regional/national level/other } \\
\hline Awofeso et al $2008^{48}$ & Australia, New South Wales & Justice health services & Smoking cessation in prisoners & Y & $\mathrm{N}$ & Y & Y \\
\hline Green et al $2006^{49}$ & Canada, British Colombia & Vancouver Island Health Authority & Provision of recommended/evidence-based care for patients with chronic conditions & Y & Y & N & $\mathrm{N}$ \\
\hline Klaiman et al $2013^{50}$ & USA, nine states & Local Health Departments & Extensive local differences in public clinic vaccination processes & Y & Y & N & N \\
\hline Klaiman et al $2014^{51}$ & USA, nine states & Local Health Departments & Extensive local differences in school-based vaccination distribution & Y & Y & N & N \\
\hline Naimoli et al $2008^{52}$ & Sub-Saharan Africa, six countries & National health departments & Substantial variation in immunisation coverage to reduce childhood mortality & Y & Y & N & N \\
\hline \multicolumn{8}{|l|}{ Primary and secondary care } \\
\hline Assefa et al $2014^{53}$ & Ethiopia, national & $\begin{array}{l}\text { Tertiary/general hospitals and health } \\
\text { centres }\end{array}$ & Patient retention in antiretroviral treatment programmes & Y & N & N & N \\
\hline \multicolumn{8}{|c|}{$\begin{array}{l}\text { *Stages from the Bradley et al process for positive deviance. }{ }^{7} \text { Y, yes—-stage addressed; } N \text {, no-stage not addressed; ?, unclear whether stage addressed. } \\
\text { Rows represent included articles ( } n=37) \text {. Rows grouped by colour (grey or white) represent unique positive deviance projects ( } n=22 \text { ). } \\
\text { MRSA, methicillin-resistant Staphylococcus aureus; VA, Veterans Affairs; VAMC, Veterans Affairs Medical Centre. }\end{array}$} \\
\hline
\end{tabular}


Table 3 Key themes within healthcare definitions of positive deviance

\begin{tabular}{|c|c|c|}
\hline Theme & Description & Examples \\
\hline $\begin{array}{l}\text { Positively deviant groups or } \\
\text { individuals are high } \\
\text { performers }\end{array}$ & $\begin{array}{l}\text { Positive deviants succeed, find better solutions and } \\
\text { achieve better outcomes than others }\end{array}$ & $\begin{array}{l}\text { 'This approach emphasizes in-depth qualitative study of } \\
\text { organizations with exceptionally high performance to } \\
\text { understand the factors that contribute to their excellence' } \\
\text { (ref. } 25, \text { p. 1542) } \\
\text { 'The positive deviance approach is a framework for } \\
\text { identifying and learning from top performers in a system' } \\
\text { (ref. 51, p.64) }\end{array}$ \\
\hline $\begin{array}{l}\text { Positively deviant groups or } \\
\text { individuals do things } \\
\text { differently }\end{array}$ & $\begin{array}{l}\text { Positive deviants follow uncommon or special practises } \\
\text { and behaviours. Only a few studies explicitly define } \\
\text { positively deviant behaviours as being 'deviant' or going } \\
\text { against cultural norms. }{ }^{30-32}\end{array}$ & $\begin{array}{l}\text { 'Positive deviance inquiries focus on individuals who behave } \\
\text { differently from the rest of the community and, in so doing, } \\
\text { succeed where others fail' (ref. 11, p.1413) } \\
\text { 'The group that faces the problem determines the desired } \\
\text { outcome; identifies the most effective behaviours, resources, } \\
\text { and actions; and searches for the best solutions using } \\
\text { unique strategies' (ref. } 39, \text { p. 946) }\end{array}$ \\
\hline $\begin{array}{l}\text { The positive deviance } \\
\text { approach is a 'bottom up' } \\
\text { approach }\end{array}$ & $\begin{array}{l}\text { The positive deviance approach is driven by the } \\
\text { community. Success is internally generated rather than } \\
\text { externally imposed }\end{array}$ & $\begin{array}{l}\text { 'The positive deviance process is grounded on several } \\
\text { beliefs. First, much of the expertise and experience needed } \\
\text { for change exist in the organization, and second, change } \\
\text { efforts are best led from within the institution by people } \\
\text { with first-hand knowledge of its work, history and norms, } \\
\ldots \text {. Third, expertise within an organization is widely } \\
\text { distributed, necessitating the engagement of staff from } \\
\text { various services, levels and roles' (ref. 34, p.234) } \\
\text { 'Since solutions originated from within, positive deviance is } \\
\text { inherently a culturally appropriate development approach.' } \\
\text { (ref. 43, p.145) }\end{array}$ \\
\hline $\begin{array}{l}\text { Positively deviant solutions } \\
\text { are sustainable within current } \\
\text { resources }\end{array}$ & $\begin{array}{l}\text { Positive deviants face similar challenges to others and } \\
\text { succeed using existing resources }\end{array}$ & $\begin{array}{l}\text { 'Positive deviance is a behavioural change approach that } \\
\text { assumes the existence in any community of individuals who } \\
\text { handle situations more effectively (positive deviants) than } \\
\text { their peers, despite the similarities of problems and available } \\
\text { resources' (ref. } 39, \text { p.946) } \\
\text { 'Positive deviance is an 'assets-based', four-stage approach } \\
\text { that focuses on using the resources already available among } \\
\text { communities to promote health'(ref. } 48, \text { p.72) }\end{array}$ \\
\hline
\end{tabular}

Although limited detail in articles hindered assessment, positive deviants were most frequently identified as organisations (eg, high-performing hospitals ${ }^{29}$ and primary healthcare units ${ }^{54}$ ) or individuals (eg, physicians $^{22}$ or nurses and patients ${ }^{11}$ ). Only one study explicitly identified positively deviant teams. ${ }^{49}$ When identifying positive deviants, various characteristics were accounted for including the context and inclusion of high-risk settings, ${ }^{245051}$ ensuring coverage of diverse characteristics and confounding variables ${ }^{20} 21232930$ and selecting a convenient sample. ${ }^{5253}$

Many articles provided limited or no detail about what criteria constituted positive deviance (see online supplementary file 4). Performance was typically ranked and positive deviants were classified as the highest performers, or those among the highest performers. ${ }^{10} 2021293054$ Qualitative criteria included vague descriptions of staff attitudes ${ }^{37} 38$ and more thorough descriptions of health status and behaviours, for example, being a thriving newborn. ${ }^{24}$ Although positive deviants were typically classified by extreme high performance, one study identified $40 \%$ of their sample. ${ }^{41}$ Nine projects assessed performance over time-commonly between 1 and 2 years. For these studies, positive deviance was therefore classified as consistent rather than one of success (see online supplementary file 4). ${ }^{1120-22} 25293033415254$
Stage 2-generating hypotheses about how positive deviants succeed Stage 2 was addressed in 29 articles (table 2), the majority of which used qualitative methods to explore how positive deviants succeed (see online supplementary file 4). All but four of these studies conducted individual interviews, ${ }^{10} 343646$ and 10 articles used focus groups or Discovery and Action Dialogues (DADs-facilitated group conversations). ${ }^{34}$ Individual/ group interviews were often combined with observation, site visits and document analysis. Many studies used extensive resources, for example, conducting 158 interviews with 11 site visits lasting 1 or 2 days each. $^{29} 30 \quad 32$ Only five projects used single or less-intensive qualitative methods. ${ }^{10} 202627365051$

Stage 2 was conducted using quantitative, routinely collected data and/or surveys in four projects. ${ }^{22} 232833$ Mixed methods were used in four additional projects, typically combining interviews, focus groups or DADs with surveys and routinely collected data. ${ }^{11} 2135$ 37-39 Twelve projects included comparison groups to assess how positive deviants differed from others (see online supplementary file 4). These usually comprised negative deviants (worst performers) and those of varying performance levels. Interestingly six projects indiscriminately included everyone regardless of performance level, and seven projects only sampled positive deviants. 
While exploring how positive deviants succeed, six projects did not outline which factors had been assessed. 2233 37-3941444648 This review intended to classify positively deviant behaviours according to the Systems Engineering Initiative for Patient Safety 2 model ${ }^{55}$ however, limited detail about how positive deviants achieved success prevented this.

\section{Stage 3-testing positively deviant strategies}

Stage 3 was conducted to a limited extent in six studies (table 2). Surveys or quantitative data collection following an intervention were the most commonly used methods, although one study combined this with focus groups. ${ }^{41}$ Bradley et $a l^{31}$ were the only authors to truly test positively deviant hypotheses within larger, more representative samples. They scaled up from 11 to 533 hospitals using a web-based survey. Half of the studies did not test hypotheses beyond the initial study site. ${ }^{28} 4148$

Stage 4-disseminating positively deviant strategies

Dissemination was reported in six articles (table 1), although they lacked detail about how interventions were designed and implemented. ${ }^{34} 48$ The most comprehensive account reviewed positively deviant findings at community meetings and created action plans to address high infant mortality ratios. ${ }^{24}$ Three studies disseminated a methicillin-resistant Staphylococcus aureus (MRSA) prevention bundle but did not report how positive deviance was applied or what results were gained. $^{42} 4547$

\section{Involvement of healthcare staff and patients}

Textual, qualitative descriptions of studies were used to explore whether staff and patients or external research teams typically set up and conducted the positive deviance projects. Healthcare staff were involved solely as participants for interviews and focus groups and the like in 18 articles (for examples see Gabbay et al, ${ }^{21}$ Abrahamson et $a l,{ }^{26}$ and Klaiman et al. ${ }^{50}$ Beyond this, staff were not integral to implementing the positive deviance approach. They did not choose the problem, identify the positive deviants or conduct the qualitative enquiries. Limited staff involvement was facilitated through designing materials, ${ }^{31}$ identifying positive deviants 24303252 and consulting on the success strategies identified. 2841 Front-line staff were integral throughout four unique projects (12 articles) which used DADs to explore success. $^{34-40}$ 43-47 These articles though lacked detail about how the DADs were conducted and tended to be of lower quality. This was particularly pertinent for the Veterans Affairs research where quality ranged from $2.1 \%$ to $8.3 \%$. $^{42-47}$

Patients were involved in two unique projects. One study identified and interviewed positively deviant patients, ${ }^{11}$ while the other engaged patients in identifying positively deviant solutions, but did not explain how this was done. ${ }^{44} 46$

\section{Quality assessment}

Overall study quality was low, ranging from $2.1 \%$ to $50.0 \%$, with an average score of $23.3 \%$. Some common concerns arose. Few studies justified their sample size, data collection tools or analysis methods. Detailed recruitment data were not provided, for example, studies using DADs did not report the number of positive deviants and/or staff involved. ${ }^{34-40}$ 42-47 At times limited detail made it difficult to identify which stage/s of the positive deviance process had been conducted. This was especially pertinent for stages 3 and 4, and is exemplified by the Veterans Affairs project. Here it was unclear how studies linked together, what methods were used to implement the approach, whether a process was followed and, in most cases, what positively deviant behaviours were identified. $^{42-47}$

Only a handful of studies used theory or frameworks to guide their qualitative enquiry, 10345051 and the factors investigated were rarely justified. Finally, data collection procedures were inadequately described in most articles. This is concerning as limited guidance on the approach currently exists. ${ }^{8}$

\section{DISCUSSION}

This systematic review synthesises healthcare applications of the positive deviance approach. Although studies vary in their focus, setting and location, positive deviance is frequently applied within secondary care, as is common within the quality improvement literature. ${ }^{56}$

\section{Applications lack quality and detail}

Using a validated tool, studies applying the positive deviance approach in healthcare were found to be low in quality; consideration and justification for study designs and methods were frequently missing, and key details were omitted. Interestingly, the positive deviance systematic review on childhood malnutrition also highlighted incomplete reporting and poor quality literature. $^{12}$

The multi-method nature of the positive deviance approach precludes the use of randomised control trials and purely quantitative designs which are typically coveted within healthcare. ${ }^{57}$ In addition, researchers are yet to agree on universal quality indicators and guidance for reporting qualitative methods. ${ }^{58}$ This may have contributed to the poor quality and lack of detail observed, although the problem is likely compounded by limited guidance on how to implement the approach. Consequently, we cannot conclude whether study limitations are due to poor quality design and methods, insufficient reporting or inadequate guidance.

As seen more widely within the quality improvement literature, ${ }^{56}$ details were particularly lacking where the positive deviance approach had been applied within complex interventions. Although it is often difficult to disentangle the effects of multiple 
interventions, as a minimum, researchers should assess and report whether positive deviance has been implemented appropriately.

\section{Defining positive deviance}

Healthcare definitions of positive deviance shared similarities with each other, and with those used in other industries and settings. ${ }^{59}$ Nevertheless, it is concerning the frequency with which limited or no definitions and/or processes were reported. Detailed definitions and explanations of how to implement positive deviance are paramount due to the novelty of this approach within healthcare. An exemplar definition would fully describe all aspects of the approach including its focus on exceptional performance, the importance of community involvement and the ability to succeed through different or deviant behaviours while facing the same resource constraints as others. Information about the process followed must also be provided. Without this the ability to critically assess literature and build on previous shortcomings is limited. If researchers wish to understand the effectiveness of improvement approaches, then precise definitions, categorisation and operationalisation are required. ${ }^{56}$ Furthermore, research is required to understand the mechanisms and/or theories of change which underpin the positive deviance approach.

Further exploration of how to define 'deviance' is warranted. Positive deviants-whether they be individuals, teams or organisations-can be defined and identified in four different ways: statistically, based on their extreme conformity, through others' reactions, or in comparison to norms. ${ }^{60}$ Within healthcare there may be implications to the definitions used; for example, despite an individual's honourable intentions, deviating from clinical guidelines could result in the loss of professional registration. Within this review, limited detail hindered assessments of whether positive deviants succeed through truly 'deviant'/'different' behaviours or whether they simply performed better along a continuum. If success is achieved through non-deviant means, then one might question whether the positive deviance approach is being applied. We may just be learning from high performers ${ }^{61}$ or those with resilience ${ }^{5}$ and the approach would therefore be better served by a more appropriate title.

\section{Study design and methods used}

Research focused on the first two stages of the positive deviance process using quantitative and qualitative methods as suggested by Bradley et al. ${ }^{7}$ Despite this, various concerns arose from the study designs and methods chosen. Some studies did not clarify who the positive deviants were and how they had been identified, if indeed, they had been identified at all. The criteria used often appeared arbitrary and cut-off points were not justified, that is, it was unclear which individuals, teams or organisations were or were not classified as positively deviant. Vague definitions of the approach compound this problem making it difficult to generate criteria and thus identify positive deviants. In addition, a lack of comparison groups restricted assessments of whether success strategies were unique to positive deviants or in fact common across communities.

Theory and/or frameworks were rarely used to explore positively deviant behaviours. Consequently we cannot conclude whether the factors influencing performance have been comprehensively assessed or whether success was achieved through unobserved or unmeasured behaviours. ${ }^{62}$ Theory can also help structure literature and facilitate comparisons between studies of a similar nature. ${ }^{62}$

The third and fourth stages of the positive deviance process were rarely conducted, or even acknowledged as subsequent steps. The novelty of the literature field may mean that this research is ongoing. Alternatively, the resources required to 'scale up' projects may have reduced the feasibility of conducting these stages. Where stages 3 and 4 have been conducted, more rigorous designs and methods should have been used. Bradley $e a^{31}$ report the most comprehensive testing of positively deviant strategies (stage 3), although attempts should be made to assess causality, not just correlation. ${ }^{63}$ More research addressing these stages is required to evaluate the effectiveness of the approach.

\section{Community involvement}

The short-lived, modest or negligible effects of topdown, complex interventions are frequently attributed to differing contexts and inadequate community involvement. ${ }^{3} 64$ The positive deviance approach involves healthcare staff throughout the process and identifies context-specific behaviours that are already used to succeed. This review however observed very little community involvement, a finding which was replicated by the previous systematic review on childhood malnutrition. ${ }^{12}$ Engaging staff more broadly in quality improvement projects is known to be difficult ${ }^{2}$ therefore, applying positive deviance within complex and demanding healthcare settings is likely to present further challenges. Research must identify practical, yet robust methods to facilitate staff involvement and should explore the level of community involvement required to maximise outcomes.

\section{Relationships between quality, methods and involvement} Two polarised observations emerged through this review. Studies which intensively involved healthcare staff commonly used word of mouth/observation and DADs to conduct stages 1 and 2. These studies were of lower quality, predominantly due to a lack of detail. In contrast, higher quality studies were typically conducted by external research teams who used 
extensive methods and resources. Staff involvement was minimal other than as participants.

Quality improvement approaches should be practical enough for clinical health professionals to implement on the front line. The positive deviance approach requires feasible and efficient methods which maintain rigour and quality while effectively involving staff and patients. Within the current literature, this balance is yet to be struck.

\section{Review limitations}

Limitations of this review should be considered alongside its findings. Despite an inclusive search strategy, relevant articles may not have been identified. Articles may not have explicitly stated that positive deviance was applied, and publication lags may have biased the research available for stages three and four of the process. Excluding grey literature and non-peerreviewed articles may have overestimated the quality of the literature field. This however supports findings that the approach is inadequately defined, and the quality of applications is low.

Poor reporting may have led to an unduly negative assessment of quality. Future applications of positive deviance should provide sufficient detail so that methods can be replicated and refined. Finally, this review cannot assess how study designs and methods are associated with the effectiveness of the approach. Calculations of effect sizes are precluded by the limited number of applications, the focus on heterogeneous outcomes and use of qualitative methods.

\section{Implication and recommendations}

The positive deviance approach has great potential to improve the quality of healthcare, as solutions are likely to be sustainable, acceptable to staff and feasible within current resources. ${ }^{6}$ Despite the 'bottom up' philosophy, most applications have been conducted by external research teams. The following recommendations are put forward to develop the positive deviance approach and make it more accessible to front-line clinical health professionals and the wider improvement community.

1. Studies must clearly define the positive deviance approach and specific process followed.

2. The methods and criteria used to identify positive deviants must always be stated regardless of whether they are exceptionally performing individuals, teams or organisations. Issues regarding reliability and validity of the data analysed should also be discussed.

3. The quality and reporting of literature can be improved by using relevant elements of research reporting guidelines such as CONSORT and SQUIRE. ${ }^{65} 66$

4. Authors should clarify whether the success strategies identified are considered deviant, different or just better than those used by others.

5. A theoretical approach should be taken to identify and define positively deviant success strategies in order to facilitate appropriate generalisations across problems and topics.

\section{Conclusion}

Various shortcomings are observed within healthcare applications of the positive deviance approach, not all of which are unique to this setting. ${ }^{12}$ The quality of methods and reporting needs to improve, theories and frameworks should be applied and comparison groups must be used to ensure factors are comprehensively assessed and that hypotheses can be attributed solely to positive deviants. Additional research and discussion among academics and clinicians is required to find a balance between using practicable methods, maintaining quality and involving healthcare staff throughout the positive deviance process.

Finally, research targeting the latter stages of the process is required to assess and compare the effectiveness of positive deviance with alternative improvement approaches. Effectiveness reviews are rarely conducted within quality improvement research, but they are necessary to help organisations decide which approach to use and how best to invest their scarce resources. $^{56}$

Twitter Follow Natalie Taylor at @njt14, Ruth Baxter at @ RuthMBaxter, Ian Kellar at @DrIanKellar, Rebecca Lawton at@LawtonRebecca

Acknowledgements The authors thank The Health Foundation for funding the $\mathrm{PhD}$ studentship through which this systematic review was completed. RB, IK and RL are members of the

Evidence-Based Transformation Theme of the National Institute for Health Research Collaboration for Leadership in Applied Health Research and Care Yorkshire and Humber (NIHR CLAHRC YH). This report presents independent research by the NIHR CLAHRC YH (http://www.clahrc-yh.nir.ac.uk). The views and opinions expressed are those of the authors and not necessarily those of the NHS, the NIHR or the Department of Health.

Contributors All authors developed the concept for this systematic review. RB designed the study and conducted the searches, screening, data extraction and analysis with input at all stages from IK, NT and RL. RB drafted the manuscript and all authors provided comments and approved the final version.

Funding Health Foundation ( $\mathrm{PhDs}$ in Improvement Science).

Competing interests None declared.

Provenance and peer review Not commissioned; externally peer reviewed.

Data sharing statement Supporting documents relevant to the results of this review have been submitted as supplementary files. Extracted data, which are not included within this report, are available on request.

Open Access This is an Open Access article distributed in accordance with the Creative Commons Attribution Non Commercial (CC BY-NC 4.0) license, which permits others to distribute, remix, adapt, build upon this work noncommercially, and license their derivative works on different terms, provided the original work is properly cited and the use is non-commercial. See: http://creativecommons.org/licenses/by$\mathrm{nc} / 4.0 /$

\section{REFERENCES}

1 The Health Foundation. Quality improvement made simple. London, UK: The Health Foundation, 2013. 
2 Dixon-Woods M, McNicol S, Martin G. Ten challenges in improving quality in healthcare: lessons from the Health Foundation's programme evaluations and relevant literature. BMJ Qual Saf 2012;21:876-84.

3 Hawe P, Shiell A, Riley T. Theorising interventions as events in systems. Am J Community Psychol 2009;43:267-76.

4 Bisognano M, Schummers D. Flipping healthcare: an essay by Maureen Bisognano and Dan Schummers. BMJ 2014;349: g5852.

5 Hollnagel E, Braithwaite J, Wears RL. Resilient health care. UK: Ashgate, 2013.

6 Marsh DR, Schroeder DG, Dearden KA, et al. The power of positive deviance. Br Med J 2004;329:1177-9.

7 Bradley EH, Curry LA, Ramanadhan S, et al. Research in action: using positive deviance to improve quality of health care. Implement Sci 2009;4:25.

8 Lawton R, Taylor N, Clay-Williams R, et al. Positive deviance: a different approach to achieving patient safety. BMJ Qual Saf 2014;3:880-3.

9 Pascale RT, Sternin J. Your company's secret change agents. Harv Bus Rev 2005;83:72-81, 153.

10 Griffith JR, Fear KM, Lammers E, et al. A positive deviance perspective on hospital knowledge management: analysis of Baldrige Award recipients 2002-2008. J Healthc Manag 2013;58:187-203.

11 Kim YM, Heerey M, Kols A. Factors that enable nurse-patient communication in a family planning context: a positive deviance study. Int J Nurs Stud 2008;45:1411-21.

12 Bisits Bullen PA. The positive deviance/hearth approach to reducing child malnutrition: Systematic review. Trop Med Int Health 2011;16:1354-66.

13 Moher D, Liberati A, Tetzlaff J, et al., The PRISMA Group. Preferred Reporting Items for Systematic Reviews and Meta-Analyses: the PRISMA statement. BMJ 2009;339:b2535.

14 Baxter R, Taylor N, Kellar I, et al. How is the positive deviance approach applied within healthcare organisations? A systematic review of the methods used. PROSPERO 2014: CRD42014009365. http://wwwcrdyorkacuk/PROSPERO/ display_recordasp? $\mathrm{ID}=\mathrm{CRD} 42014009365$

15 Landis JR, Koch GG. The measurement of observer agreement for categorical data. Biometrics 1977;33:159-74.

16 Sirriyeh R, Lawton R, Gardner P, et al. Reviewing studies with diverse designs: the development and evaluation of a new tool. J Eval Clin Pract 2012;18:746-52.

17 Popay J, Roberts H, Sowden A, et al. Guidance on the conduct of narrative synthesis in systematic reviews: a product from the ESRC Methods Programme. 2006. http://www.lancs.ac.uk/shm/ research/nssr/research/dissemination/publications (accessed 4 Apr 2014).

18 Arai L, Britten N, Popay J, et al. Testing methodological developments in the conduct of narrative synthesis: a demonstration review of research on the implementation of smoke alarm interventions. Evid Policy 2007;3:361-83.

19 Centre for Reviews and Dissemination. Systematic reviews: CRD's guidance for undertaking reviews in health care. UK: CRD, University of York, 2009.

20 Taliani CA, Bricker PL, Adelman AM, et al. Implementing effective care management in the patient-centered medical home. Am J Manag Care 2013;19:957-64.

21 Gabbay RA, Friedberg MW, Miller-Day M, et al. A positive deviance approach to understanding key features to improving diabetes care in the medical home. Ann Fam Med 2013;11 (Suppl 1):S99-107.
22 Kraschnewski JL, Sciamanna CN, Pollak KI, et al. The epidemiology of weight counseling for adults in the United States: A case of positive deviance. Int J Obes (Lond) 2013;37:751-3.

23 Ma P, Magnus JH. Exploring the concept of positive deviance related to breastfeeding initiation in Black and White WIC enrolled first time mothers. Matern Child Health J 2012;16:1583-93.

24 Marsh DR, Sternin M, Khadduri R, et al. Identification of model newborn care practices through a positive deviance inquiry to guide behavior-change interventions in Haripur, Pakistan. Food Nutr Bull 2002;23(4 Suppl):109-18.

25 Rose AJ, Petrakis BA, Callahan P, et al. Organizational characteristics of high- and low-performing anticoagulation clinics in the Veterans Health Administration. Health Serv Res 2012;47:1541-60.

26 Abrahamson K, Durham M, Norton K, et al. Delivery of psychosocial care for cancer patients: a pilot investigation. Stud Health Technol Inform 2011;164:32-6.

27 Abrahamson K, Durham M, Norton K, et al. Provision of psychosocial care for cancer patients: service delivery in urban and rural settings. J Prim Care Community Health 2011;2:220-4.

28 Anzarut A, Martens B, Tredget E. Improving journal clubs through the use of positive deviance: a mixed-methods study. Can J Plast Surg 2011;19:82-4.

29 Curry LA, Spatz E, Cherlin E, et al. What distinguishes top-performing hospitals in acute myocardial infarction mortality rates? Ann Intern Med 2011;154:384-90.

30 Cherlin EJ, Curry LA, Thompson JW, et al. Features of high quality discharge planning for patients following acute myocardial infarction. J Gen Intern Med 2013;28: 436-43.

31 Bradley EH, Curry LA, Spatz ES, et al. Hospital strategies for reducing risk-standardized mortality rates in acute myocardial infarction. Ann Intern Med 2012;156:618-26.

32 Landman AB, Spatz ES, Cherlin EJ, et al. Hospital collaboration with emergency medical services in the care of patients with acute myocardial infarction: perspectives from key hospital staff. Ann Emerg Med 2013;61:185-95.

33 Kennedy TS, Oakland JM, Shaw RD. Growth patterns and nutritional factors associated with increased head circumference at 18 months in normally developing, low-birth-weight infants. J Am Diet Assoc 1999;99:1522-6.

34 Lindberg C, Schneider M. Combating infections at Maine Medical Center: insights into complexity-informed leadership from positive deviance. Leadership 2013;9:229-53.

35 Lindberg C, Downham G, Buscell P, et al. Embracing collaboration: A novel strategy for reducing bloodstream infections in outpatient hemodialysis centers. Am J Infect Control 2013;41:513-19.

36 Downham G, Jones E, Peterson P, et al. Reducing bloodstream infections in an outpatient hemodialysis center-New Jersey, 2008-2011. JAMA 2012;307:2250-2.

37 Marra AR, Guastelli LR, De Araujo CMP, et al. Positive deviance: A new strategy for improving hand hygiene compliance. Infect Control Hosp Epidemiol 2010;31:12-20.

38 Marra AR, Guastelli LR, Pereira de Araujo CM, et al. Positive deviance: A program for sustained improvement in hand hygiene compliance. Am J Infect Control 2011;39:1-5.

39 De MacEdo RDCR, Oliveira Jacob EM, Da Silva VP, et al. Positive deviance: Using a nurse call system to evaluate hand hygiene practices. Am J Infect Control 2012;40:946-50. 
40 Marra AR, Noritomi DT, Westheimer Cavalcante AJ, et al. A multicenter study using positive deviance for improving hand hygiene compliance. Am J Infect Control 2013;41:984-8.

41 Zaidi Z, Jaffery T, Shahid A, et al. Change in action: using positive deviance to improve student clinical performance. Adv Health Sci Educ Theory Pract 2012;17:95-105.

42 Awad SS, Palacio CH, Subramanian A, et al. Implementation of a methicillin-resistant Staphylococcus aureus (MRSA) prevention bundle results in decreased MRSA surgical site infections. Am J Surg 2009;198:607-10.

43 Bonuel N, Byers P, Gray-Becknell T. Methicillin Resistant Staphylococcus Aureus (MRSA) prevention through facility-wide culture change. Crit Care Nurs Q 2009;32:144-8.

44 Ellingson K, Muder RR, Jain R, et al. Sustained reduction in the clinical incidence of methicillin-resistant Staphylococcus aureus colonization or infection associated with a multifaceted infection control intervention. Infect Control Hosp Epidemiol 2011;32:1-8.

45 Evans ME, Kralovic SM, Simbartl LA, et al. Prevention of methicillin-resistant Staphylococcus aureus infections in spinal cord injury units. Am J Infect Control 2013;41:422-6.

46 Forsha B, Richmond I. Best practice protocols: reducing harm from MRSA. Nurs Manage 2007;38:22-7.

47 Jain R, Kralovic SM, Evans ME, et al. Veterans Affairs initiative to prevent methicillin-resistant staphylococcus aureus infections. N Engl J Med 2011;364:1419-30.

48 Awofeso N, Irwin T, Forrest G. Using positive deviance techniques to improve smoking cessation outcomes in New South Wales prison settings. Health Promot J Austr 2008;19:72-3.

49 Green CJ, Fortin P, Maclure M, et al. Information system support as a critical success factor for chronic disease management: Necessary but not sufficient. Int J Med Inform 2006;75:818-28.

50 Klaiman T, O'Connell K, Stoto M. Local health department public vaccination clinic success during 2009 pH1N1. J Public Health Manag Pract 2013;19:E20-6.

51 Klaiman T, O'Connell K, Stoto MA. Learning from successful school-based vaccination clinics during 2009 pH1N1. J Sch Health 2014;84:63-9.

52 Naimoli JF, Challa S, Schneidman M, et al. Toward a grounded theory of why some immunization programmes in sub-Saharan Africa are more successful than others: a descriptive and exploratory assessment in six countries. Health Policy Plan 2008;23:379-89.

53 Assefa Y, Lynen L, Wouters E, et al. How to improve patient retention in an antiretroviral treatment program in Ethiopia: a mixed-methods study. BMC Health Serv Res 2014;14:45.

54 Bradley EH, Byam P, Alpern R, et al. A systems approach to improving rural care in Ethiopia. PLOS ONE 2012;7:e35042.
55 Holden RJ, Carayon P, Gurses AP, et al. SEIPS 2.0: A human factors framework for studying and improving the work of healthcare professionals and patients. Ergonomics 2013;56:1669-86.

56 Alexander JA, Hearld LR. What can we learn from quality improvement research? A critical review of research methods. Med Care Res Rev 2009;66:235-71.

57 Evans D. Hierarchy of evidence: a framework for ranking evidence evaluating healthcare interventions. J Clin Nurs 2003;12:77-84.

58 Garside R, Pearson M, Moxham T. What influences the uptake of information to prevent skin cancer? A systematic review and synthesis of qualitative research. Health Educ Res 2010;25:162-82.

59 Schooley J, Morales L. Learning from the community to improve maternal-child health and nutrition: the positive deviance/hearth approach. J Midwifery Womens Health 2007;52:376-83.

60 Spreitzer GM, Sonenshein S. Toward the construct definition of positive deviance. Am Behav Sci 2004;47:828-47.

61 Nelson EC, Batalden PB, Huber TP, et al. Microsystems in health care: Part 1. Learning from high-performing front-line clinical units. Jt Comm J Qual Patient Saf 2001;28:472-93.

62 Michie S, Prestwich A. Are interventions theory-based? Development of a theory coding scheme. Health Psychol 2010;29:1-8.

63 Alexander JA, Hearld LR. The science of quality improvement implementation. Developing capacity to make a difference. Med Care 2011;49(Suppl 1):S6-20.

64 Hawe P. Lessons from complex interventions to improve health. Annu Rev Public Health 2015;36:307-23.

65 Ogrinc G, Mooney SE, Estrada C, et al. The SQUIRE (Standards for QUality Improvement Reporting Excellence) guidelines for quality improvement reporting: explanation and elaboration. Qual Saf Health Care 2008;17(Suppl 1): i13-32.

66 Schulz KF, Altman DG, Moher D. CONSORT 2010 Statement: updated guidelines for reporting parallel group randomised trials. BMJ 2010;340:c332.

67 Sternin J, Choo R. The power of positive deviancy. An effort to reduce malnutrition in Vietnam offers an important lesson about managing change. Harv Bus Rev 2000;78:14-15.

68 Sparks D. From hunger aid to school reform: positive deviance approach seeks solutions that already exist. National Staff Development Council 2004;25:46-51.

69 Lapping K, Marsh DR, Rosenbaum J, et al. The positive deviance approach: Challenges and opportunities for the future. Food and Nutrition Bulletin 2002;23(4 Suppl): $130-7$. 